\title{
Research Article \\ Structural Vibration Control for a Class of Connected Multistructure Mechanical Systems
}

\author{
Francisco Palacios-Quiñonero, ${ }^{1}$ Josep M. Rossell, ${ }^{1}$ \\ Josep Rubió-Massegú, ${ }^{1}$ and Hamid R. Karimi ${ }^{2}$ \\ ${ }^{1}$ Departament de Matemàtica Aplicada III, Universitat Politècnica de Catalunya (UPC), \\ Av. Bases de Manresa 61-73, Manresa 08242, Barcelona, Spain \\ ${ }^{2}$ Department of Engineering, Faculty of Engineering and Science, University of Agder (UiA), \\ 4898 Grimstad, Norway
}

Correspondence should be addressed to Francisco Palacios-Quiñonero, francisco.palacios@upc.edu

Received 16 June 2012; Accepted 8 August 2012

Academic Editor: Zidong Wang

Copyright (C) 2012 Francisco Palacios-Quiñonero et al. This is an open access article distributed under the Creative Commons Attribution License, which permits unrestricted use, distribution, and reproduction in any medium, provided the original work is properly cited.

\begin{abstract}
A mathematical model to compute the overall vibrational response of connected multistructure mechanical systems is presented. Using the proposed model, structural vibration control strategies for seismic protection of multibuilding systems can be efficiently designed. Particular attention is paid to the design of control configurations that combine passive interbuilding dampers with local feedback control systems implemented in the buildings. These hybrid active-passive control strategies possess the good properties of passive control systems and also have the highperformance characteristics of active control systems. Moreover, active-passive control configurations can be properly designed for multibuilding systems requiring different levels of seismic protection and are also remarkably robust against failures in the local feedback control systems. The application of the main ideas is illustrated by means of a three-building system, and numerical simulations are conducted to assess the performance of the proposed structural vibration control strategies.
\end{abstract}

\section{Introduction}

Over the last years, seismic protection of adjacent buildings has been attracting an increasing interest. For this kind of systems, the action of seismic excitations can produce interbuilding collisions (pounding), which can cause severe damage to the buildings structure and contents [1-5]. Consequently, structural vibration control (SVC) strategies for multibuilding systems must aim at mitigating not only the vibrational response of individual buildings, but also the negative interbuilding interactions. 
The connected control method (CCM) is a SVC strategy for multibuilding systems that consists in linking adjacent buildings by coupling devices to provide appropriate reaction control forces. The application of the CCM using different types of passive [6-16], active [1719], and semiactive [20-23] linking devices has been extensively investigated with positive results. Recently, more complex control configurations combining passive interbuilding dampers with local feedback control systems implemented in the buildings have been proposed [24, 25]. These active-passive SVC strategies combine the good properties of passive control systems and the high-performance characteristics of active control systems [26-28]. It should be highlighted, however, that most of the research effort undertaken to date has been directed at the two-building case, while more complex multibuilding problems still remain virtually unexplored. Obtaining a suitable formulation for the dynamical response of certain classes of connected multistructure mechanical systems is one of the major obstacles that has to be overcome in order to design SVC strategies for multibuilding systems. A preliminary work in this line presenting an active-passive SVC strategy for seismic protection of a three-building system can be found in [29].

The main contribution of the present paper is twofold: (i) a mathematical model to compute the overall vibrational response of connected multistructure mechanical systems is provided. (ii) Active-passive SVC strategies for seismic protection of multibuilding systems are designed using the proposed model and the CCM approach.

The paper is organized as follows: in Section 2, a general second-order model for the unforced response of connected multistructure mechanical systems is provided. The forced response is also studied for some particular cases of special relevance in SVC. In Section 3, passive, active, and active-passive SVC strategies for seismic protection of multibuilding systems are discussed. The main ideas are presented by means of a three-building system. Finally, in Section 4, a set of numerical simulations is conducted to assess the effectiveness of the proposed control strategies.

\section{Multistructure Connected System}

In this section, we present a mathematical model to compute the dynamical response of the multistructure system $\mathcal{S}$ schematically depicted in Figure 1 . The overall system $\mathcal{S}$ consists of $p$ parallel substructures $\mathcal{S}^{(1)}, \ldots, \mathcal{S}^{(p)}$. Each substructure $\mathcal{S}^{(j)}$ is a mass-spring-damper system with $n_{j}$ degrees of freedom, and between adjacent substructures $\mathcal{S}^{(j)}$ and $\mathcal{S}^{(j+1)}$, there is a linking system $\mathcal{L}^{(j)}$ formed by a maximum number of $r_{j}=\min \left(n_{j}, n_{j+1}\right)$ spring-damper elements. The aim of this section is to obtain a proper formulation of the second-order equation that describes the overall motion of system $\mathcal{S}$ in the form

$$
M \ddot{q}(t)+C \dot{q}(t)+K q(t)=f(t),
$$

where $M$ is the global mass matrix; $C$ and $K$ are the total damping and stiffness matrices, respectively, including the internal stiffness and damping coefficients of the substructures $\mathcal{S}^{(j)}$ as well as the stiffness and damping coefficients of the linking systems $\mathcal{L}^{(j)} ; f(t)$ is the vector of external forces. 


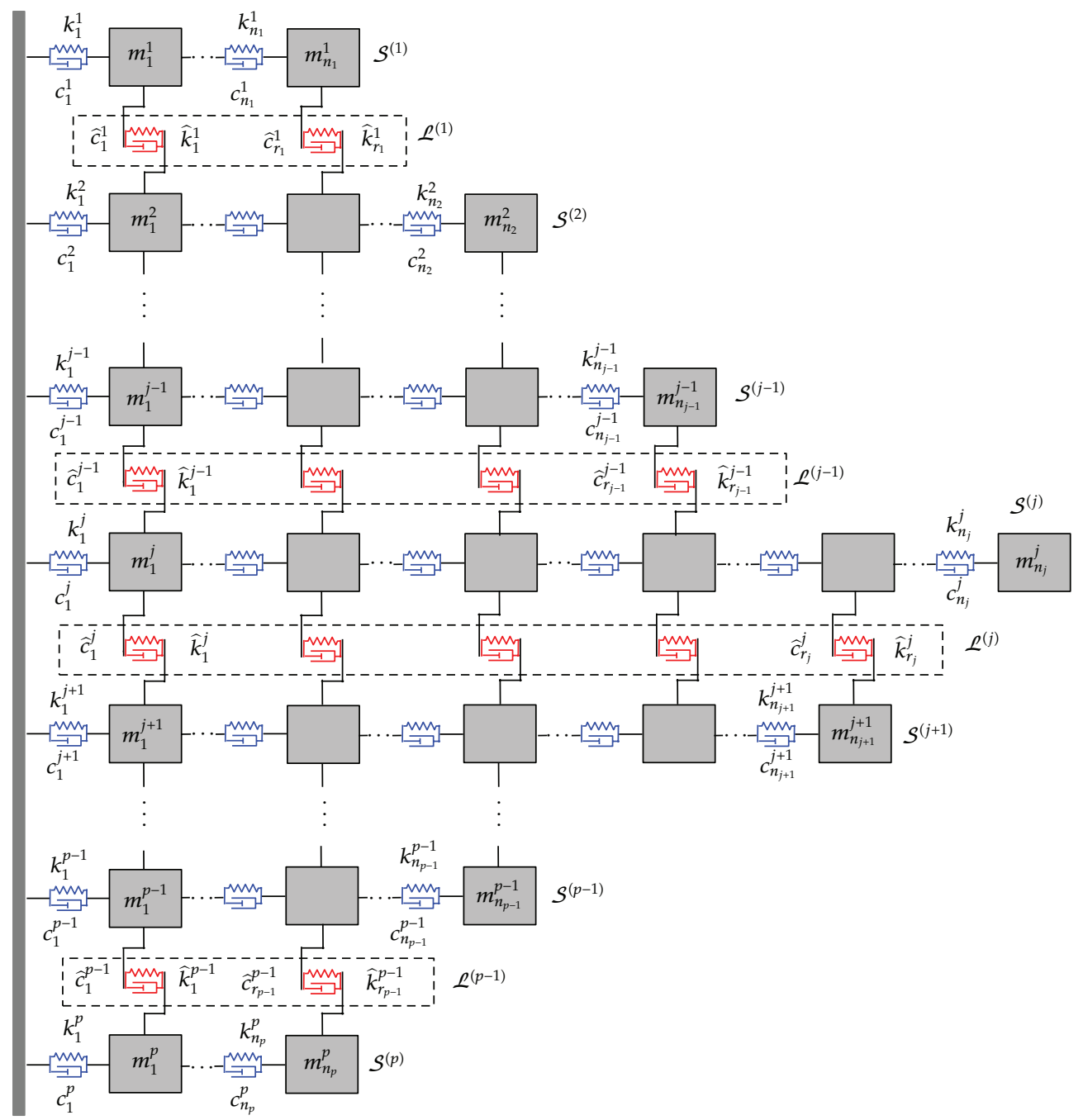

Figure 1: Multistructure system $\mathcal{S}$ formed by interconnected multiple-degree-of-freedom mass-springdamper systems $\mathcal{S}^{(j)}$.

\subsection{Unforced Response}

Let us consider the $j$ th substructure displayed in Figure 2. The vector of relative displacements is

$$
q^{(j)}(t)=\left[q_{1}^{j}(t), \ldots, q_{n_{j}}^{j}(t)\right]^{T},
$$

where $q_{i}^{j}(t)$ represents the relative displacement of the mass $m_{i}^{j}$ with respect to the fixed reference $O$, which in this subsection is assumed to be an inertial frame. 


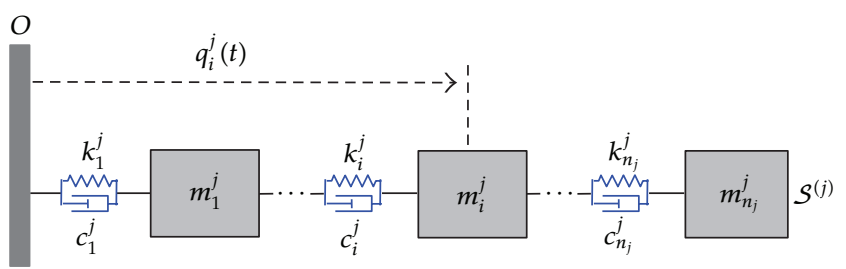

Figure 2: Multi-degree-of-freedom mass-spring-damper subsystem $\mathcal{S}^{(j)}$.

A second-order model for the substructure $\mathcal{S}^{(j)}$ can be written in the form

$$
M^{(j)} \ddot{q}^{(j)}(t)+C^{(j)} \dot{q}^{(j)}(t)+K^{(j)} q^{(j)}(t)=f_{\ell}^{(j)}(t),
$$

where $f_{\ell}^{(j)}(t)$ denotes the vector of interstructure forces resulting from the interaction between adjacent substructures through the linking elements. The mass matrix is a diagonal matrix

$$
M^{(j)}=\operatorname{diag}\left[m_{1}^{j}, \ldots, m_{n_{j}}^{j}\right],
$$

and the damping matrix has the following tridiagonal structure:

$$
C^{(j)}=\left[\begin{array}{ccccccc}
c_{1}^{j}+c_{2}^{j} & & -c_{2}^{j} & & & & \\
-c_{2}^{j} & & c_{2}^{j}+c_{3}^{j} & & -c_{3}^{j} & & \\
& \ddots & & \ddots & & \ddots & \\
& & -c_{n_{j}-1}^{j} & & c_{n_{j}-1}^{j}+c_{n_{j}}^{j} & & -c_{n_{j}}^{j} \\
& & & & -c_{n_{j}}^{j} & & c_{n_{j}}^{j}
\end{array}\right] .
$$

The stiffness matrix $K^{(j)}$ has an analogous structure and can be obtained by replacing entries $c_{i}^{j}$ by $k_{i}^{j}$ in (2.5). We also define the damping and stiffness matrices of the linking system $\mathcal{L}^{(j)}$ as follows:

$$
\widehat{C}^{(j)}=\operatorname{diag}\left[\widehat{c}_{1}^{j}, \ldots, \widehat{c}_{r_{j}}^{j}\right], \quad \widehat{K}^{(j)}=\operatorname{diag}\left[\widehat{k}_{1}^{j}, \ldots, \widehat{k}_{r_{j}}^{j}\right], \quad r_{j}=\min \left(n_{j}, n_{j+1}\right)
$$

The main difficulty in obtaining a simple formulation for the overall second-order model (2.1) arises from the fact that adjacent substructures have, in general, different number of masses. This problem can be conveniently solved by extending the damping and stiffness matrices of the linking systems with a proper number of zero rows and columns. The benefits of this simple resource are twofold: (i) a plain and elegant matrix formulation of equation (2.1), and (ii) an extremely easy computational implementation. Next, we introduce the zeroextension of matrices and provide a simple Matlab function to compute it. 


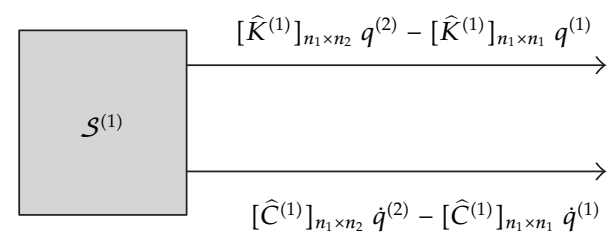

Figure 3: Force diagram for the initial substructure $\mathcal{S}^{(1)}$.

Definition 2.1. Given an $m \times n$ matrix $A$ and two integers $m^{\prime} \geq m$ and $n^{\prime} \geq n$, we define the $m^{\prime} \times n^{\prime}$ zero-extension of $A$ as the matrix

$$
[A]_{m^{\prime} \times n^{\prime}}=\left[\begin{array}{c|c}
A & {[0]_{m \times\left(n^{\prime}-n\right)}} \\
\hline[\mathbf{0}]_{\left(m^{\prime}-m\right) \times n} & {[\mathbf{0}]_{\left(m^{\prime}-m\right) \times\left(n^{\prime}-n\right)}}
\end{array}\right],
$$

obtained from $A$ by adding $m^{\prime}-m$ final zero-rows and $n^{\prime}-n$ final zero-columns.

The following Matlab function computes the matrix zero-extension:

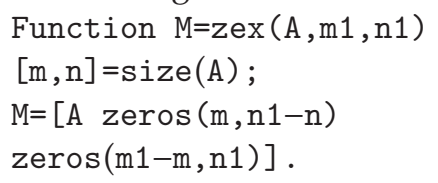

For the matrix

$$
A=\left[\begin{array}{ll}
1 & 2 \\
3 & 4
\end{array}\right]
$$

the $3 \times 5$ zero-extension can be computed with the command $z e x(A, 3,5)$, resulting

$$
[A]_{3 \times 5}=\left[\begin{array}{lllll}
1 & 2 & 0 & 0 & 0 \\
3 & 4 & 0 & 0 & 0 \\
0 & 0 & 0 & 0 & 0
\end{array}\right]
$$

To obtain the expression for the vector of linking interstructure forces $f_{\ell}^{(j)}(t)$, we consider three different cases corresponding to the relative position of the substructure $\mathcal{S}^{(j)}$ : (a) initial substructure $\mathcal{S}^{(1)}$, (b) interior substructure $\mathcal{S}^{(j)}, 1<j<p$, and (c) final substructure $\mathcal{S}^{(p)}$. For the initial substructure $\mathcal{S}^{(1)}$, from the force diagram in Figure 3 , we have

$$
f_{\ell}^{(1)}=\left[\widehat{C}^{(1)}\right]_{n_{1} \times n_{2}} \dot{q}^{(2)}-\left[\widehat{C}^{(1)}\right]_{n_{1} \times n_{1}} \dot{q}^{(1)}+\left[\widehat{K}^{(1)}\right]_{n_{1} \times n_{2}} q^{(2)}-\left[\widehat{K}^{(1)}\right]_{n_{1} \times n_{1}} q^{(1)}
$$




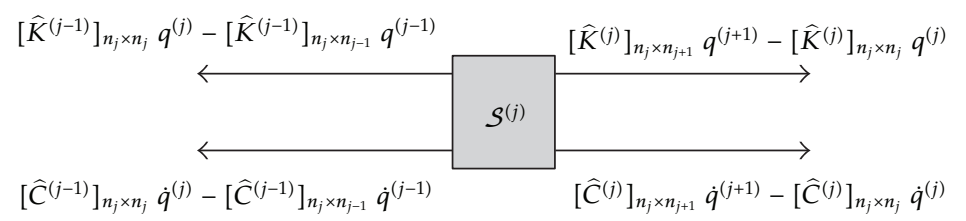

Figure 4: Force diagram for interior substructures $\mathcal{S}^{(j)}, 1<j<p$.

Equation (2.3) for $\mathcal{S}^{(1)}$ takes now the form

$$
\begin{aligned}
M^{(1)} \ddot{q}^{(1)} & +\left\{C^{(1)}+\left[\widehat{C}^{(1)}\right]_{n_{1} \times n_{1}}\right\} \dot{q}^{(1)}-\left[\widehat{C}^{(1)}\right]_{n_{1} \times n_{2}} \dot{q}^{(2)} \\
& +\left\{K^{(1)}+\left[\widehat{K}^{(1)}\right]_{n_{1} \times n_{1}}\right\} q^{(1)}-\left[\widehat{K}^{(1)}\right]_{n_{1} \times n_{2}} q^{(2)}=0 .
\end{aligned}
$$

Note that, for simplicity, the explicit dependence on time has been omitted in (2.10), (2.11), and Figure 3 , and notations like $f_{\ell}^{(1)}$ and $q^{(1)}$ have been used instead of $f_{\ell}^{(1)}(t)$ and $q^{(1)}(t)$. The same will be done in the sequel when convenient.

Analogously, from the force diagram in Figure 4, it results

$$
\begin{aligned}
f_{\ell}^{(j)}= & {\left[\widehat{C}^{(j-1)}\right]_{n_{j} \times n_{j-1}} \dot{q}^{(j-1)}-\left\{\left[\widehat{C}^{(j-1)}\right]_{n_{j} \times n_{j}}+\left[\widehat{C}^{(j)}\right]_{n_{j} \times n_{j}}\right\} \dot{q}^{(j)}+\left[\widehat{C}^{(j)}\right]_{n_{j} \times n_{j+1}} \dot{q}^{(j+1)} } \\
& +\left[\widehat{K}^{(j-1)}\right]_{n_{j} \times n_{j-1}} q^{(j-1)}-\left\{\left[\widehat{K}^{(j-1)}\right]_{n_{j} \times n_{j}}+\left[\widehat{K}^{(j)}\right]_{n_{j} \times n_{j}}\right\} q^{(j)}+\left[\widehat{K}^{(j)}\right]_{n_{j} \times n_{j+1}} q^{(j+1)},
\end{aligned}
$$

and the second-order model for $\mathcal{S}^{(j)}$ can be written as

$$
\begin{aligned}
M^{(j)} \ddot{q}^{(j)} & -\left[\widehat{C}^{(j-1)}\right]_{n_{j} \times n_{j-1}} \dot{q}^{(j-1)}+\left\{C^{(j)}+\left[\widehat{C}^{(j-1)}\right]_{n_{j} \times n_{j}}+\left[\widehat{C}^{(j)}\right]_{n_{j} \times n_{j}}\right\} \dot{q}^{(j)} \\
& -\left[\widehat{C}^{(j)}\right]_{n_{j} \times n_{j+1}} \dot{q}^{(j+1)}-\left[\widehat{K}^{(j-1)}\right]_{n_{j} \times n_{j-1}} q^{(j-1)}+ \\
& +\left\{K^{(j)}+\left[\widehat{K}^{(j-1)}\right]_{n_{j} \times n_{j}}+\left[\widehat{K}^{(j)}\right]_{n_{j} \times n_{j}}\right\} q^{(j)}-\left[\widehat{K}^{(j)}\right]_{n_{j} \times n_{j+1}} q^{(j+1)}=0 .
\end{aligned}
$$

Finally, from Figure 5, we get

$$
\begin{aligned}
f_{\ell}^{(p)}= & -\left[\widehat{C}^{(p-1)}\right]_{n_{p} \times n_{p}} \dot{q}^{(p)}+\left[\widehat{C}^{(p-1)}\right]_{n_{p} \times n_{p-1}} \dot{q}^{(p-1)} \\
& -\left[\widehat{K}^{(p-1)}\right]_{n_{p} \times n_{p}} q^{(p)}+\left[\widehat{K}^{(p-1)}\right]_{n_{p} \times n_{p-1}} q^{(p-1)},
\end{aligned}
$$




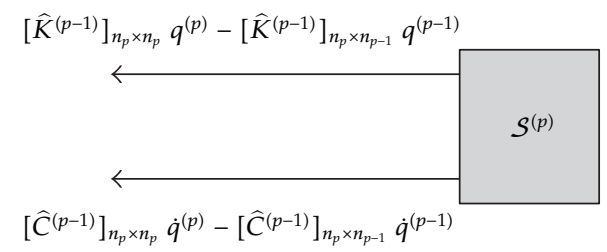

Figure 5: Force diagram for the final substructure $\mathcal{S}^{(p)}$.

and the corresponding second-order model is

$$
\begin{aligned}
M^{(p)} \ddot{q}^{(p)} & -\left[\widehat{C}^{(p-1)}\right]_{n_{p} \times n_{p-1}} \dot{q}^{(p-1)}+\left\{C^{(p)}+\left[\widehat{C}^{(p-1)}\right]_{n_{p} \times n_{p}}\right\} \dot{q}^{(p)} \\
& -\left[\widehat{K}^{(p-1)}\right]_{n_{p} \times n_{p-1}} q^{(p-1)}+\left\{K^{(p)}+\left[\widehat{K}^{(p-1)}\right]_{n_{p} \times n_{p}}\right\} q^{(p)}=0 .
\end{aligned}
$$

From (2.11), (2.13), and (2.15), we can now obtain an overall second-order model for the unforced response of the multibuilding coupled system in the form

$$
M \ddot{q}(t)+C \dot{q}(t)+K q(t)=0,
$$

where

$$
q(t)=\left[\left\{q^{(1)}(t)\right\}^{T}, \ldots,\left\{q^{(p)}(t)\right\}^{T}\right]^{T}
$$

is the overall vector of displacements. To this end, we express the global damping and stiffness matrices in the form

$$
C=\bar{C}+\widehat{C}, \quad K=\bar{K}+\widehat{K},
$$

where matrices $\bar{C}$ and $\bar{K}$ correspond to the internal damping and stiffness of the substructures, respectively, and have the following block diagonal form:

$$
\bar{C}=\operatorname{diag}\left[C^{(1)}, \ldots, C^{(p)}\right], \quad \bar{K}=\operatorname{diag}\left[K^{(1)}, \ldots, K^{(p)}\right],
$$

and matrices $C^{(j)}, K^{(j)}$ have the form given in (2.5). The damping matrix $\widehat{C}$ corresponds to the linking systems and has the tridiagonal block structure shown in Figure 6, the stiffness 


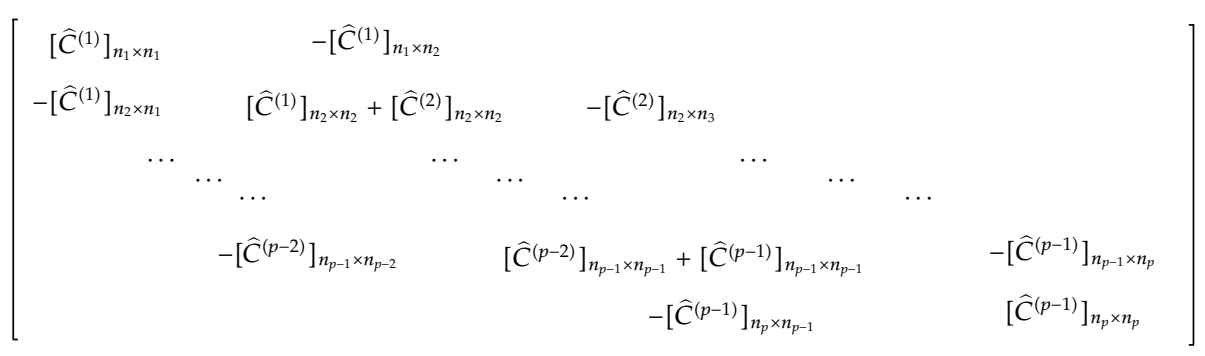

Figure 6: Damping matrix $\widehat{C}$ for the overall linking system.

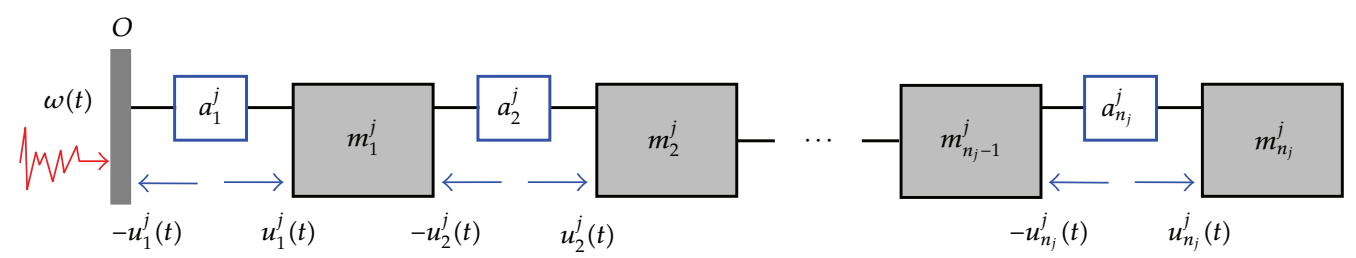

Figure 7: External excitations acting upon substructure $\mathcal{S}^{(j)}$.

matrix $\widehat{K}$ has the same structure as $\widehat{C}$ and can be obtained by replacing the entries $\left[\widehat{C}^{(j)}\right]_{n \times n^{\prime}}$ by $\left[\widehat{K}^{(j)}\right]_{n \times n^{\prime}}$. Finally, the global mass matrix $M$ is the block diagonal matrix

$$
M=\operatorname{diag}\left[M^{(1)}, \ldots, M^{(p)}\right]
$$

where $M^{(j)}, 1 \leq j \leq p$ are the substructure mass matrices given in (2.4).

\subsection{Forced Response}

Now, we assume that some external excitations are acting upon the substructures $\mathcal{S}^{(j)}$. Specifically, we will turn out our attention to the particular case schematically depicted in Figure 7, where $\omega(t)$ represents the acceleration of the reference frame $O$, and the element $a_{i}^{j}$ is a force actuation device implemented between the adjacent masses $m_{i-1}^{j}$ and $m_{i}^{j}$ that produces a pair of opposite forces of magnitude $\left|u_{i}^{j}(t)\right|$ as indicated in the figure. This case is particularly relevant for structural vibration control of seismically excited buildings, where the external acceleration corresponds to the seismic ground acceleration, and the actuation devices $a_{i}^{j}$ are interstory force actuators that implement suitable control forces to mitigate the vibrational response of the building.

A second-order model for the vibrational response of the substructure $\mathcal{S}^{(j)}$ can now be written in the form

$$
M^{(j)} \ddot{q}^{(j)}+C^{(j)} \dot{q}^{(j)}+K^{(j)} q^{(j)}-f_{\ell}^{(j)}(t)=f_{u}^{(j)}(t)+f_{\omega}^{(j)}(t),
$$


where the term $f_{u}^{(j)}(t)$ is the vector of control forces acting on $\mathcal{S}^{(j)}$, and $f_{\omega}^{(j)}(t)$ contains the inertial forces resulting from the fact that $O$ is now an accelerated reference frame. Denoting by $[1]_{n_{j} \times 1}$ the column vector with $n_{j}$ entries equal to 1 , the vector of inertial forces can be written as

$$
f_{\omega}^{(j)}(t)=-M^{(j)}[1]_{n_{j} \times 1} \omega(t)
$$

For the vector of control actions, we consider the control location matrix of size $n_{j} \times n_{j}$

$$
T_{u}^{(j)}=\left[\begin{array}{ccccc}
1 & -1 & & & \\
& 1 & -1 & & \\
& & \ddots & \ddots & \\
& & & 1 & -1 \\
& & & & 1
\end{array}\right]
$$

and the vector of control actions

$$
u^{(j)}(t)=\left[u_{1}^{j}(t), \ldots, u_{n_{j}}^{j}(t)\right]^{T},
$$

to obtain

$$
f_{u}^{(j)}(t)=T_{u}^{(j)} u^{(j)}(t)
$$

Finally, considering (2.21), (2.22), (2.25), and the results presented in the previous subsection, we can derive a second-order model for the overall vibrational response of the multistructure system $\mathcal{S}$ in the following form:

$$
M \ddot{q}(t)+C \dot{q}(t)+K q(t)=T_{u} u(t)+T_{\omega} \omega(t),
$$

where $q(t)$ is the overall displacement vector defined in (2.17); matrices $M, C, K$ are given in (2.18), (2.19), (2.20), and Figure 6; $\omega(t)$ is the external acceleration, and $T_{\omega}=-M[1]_{n \times 1}$ is the external disturbance matrix; $u(t)$ represents the overall vector of actuation forces

$$
u(t)=\left[\left\{u^{(1)}(t)\right\}^{T}, \ldots,\left\{u^{(p)}(t)\right\}^{T}\right]^{T}
$$




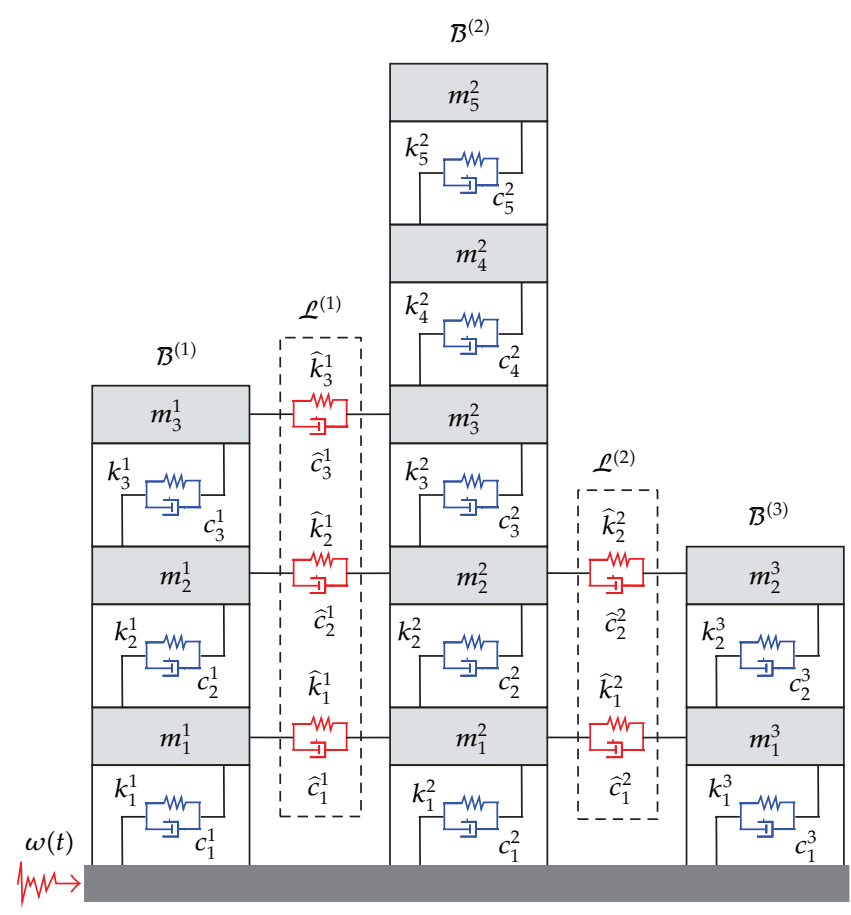

(a) Connected multibuilding model

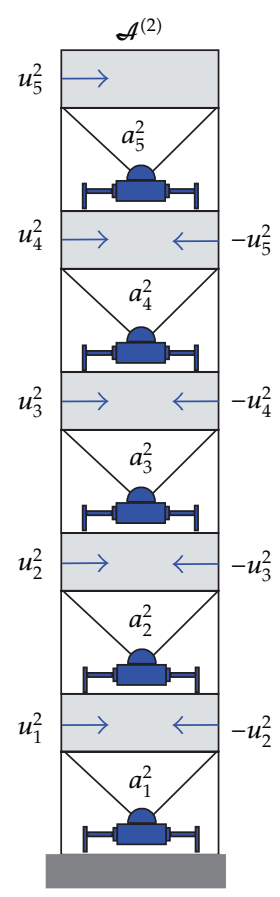

(b) Actuation scheme in $B^{(2)}$

Figure 8: Connected three-building system.

and $T_{u}$ is the overall location control matrix defined as

$$
T_{u}=\operatorname{diag}\left[T_{u}^{(1)}, \ldots, T_{u}^{(p)}\right],
$$

$n=n_{1}+\cdots+n_{p}$ is the total number of degrees of freedom, and $p$ is the number of substructures. If no active control system has been implemented in the subsystem $\mathcal{S}^{(j)}, u^{(j)}(t)$ can be taken as a zero vector and $T_{u}^{(j)}$ as a zero matrix of appropriate dimensions. The proposed model includes the action of external acceleration disturbance and active control systems implemented in the substructures and, moreover, is formally analogous to the usual formulation used in single-structure SVC problems.

\section{Structural Vibration Control Strategies for Multibuilding Systems}

In this section, we are interested in designing SVC strategies for seismic protection of multibuilding systems. For clarity and simplicity, the main ideas are presented through the three-story building system schematically depicted in SubFigure 8(a), where the central five-story building is assumed to require a special level of seismic protection. For this particular multibuilding system, four control configurations are considered: (a) activepassive, (b) passive, (c) uncoupled-active, and (d) uncontrolled. In the active-passive control configuration (see SubFigure 9(a)), an active local state-feedback control system with the 


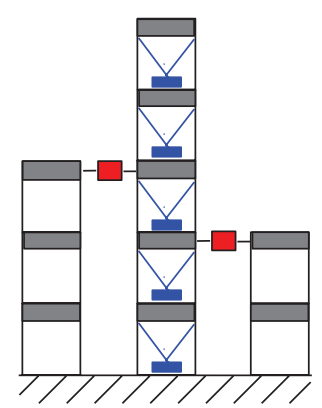

(a) Active-passive

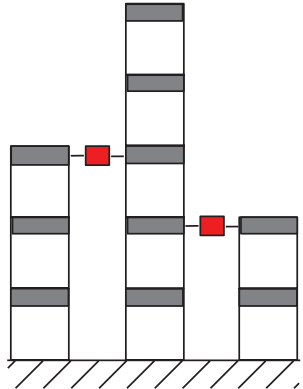

(b) Passive

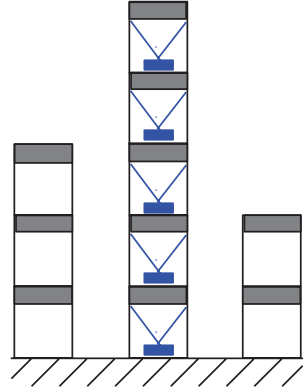

(c) Active

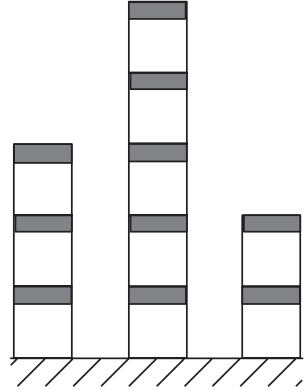

(d) Uncontrolled

Figure 9: Control configurations for the three-building system.

actuation scheme presented in SubFigure 8(b) has been implemented in the central building. Moreover, two passive dampers have been placed as interbuilding linking elements: one at the third-floor level between buildings 1 and 2 and the other at the second-floor level between building 2 and building 3. The passive control configuration (SubFigure 9(b)) only comprises the interbuilding passive dampers. In the uncoupled-active control configuration (SubFigure 9(c)), an active local feedback system has been implemented in the central building, but no passive interbuilding elements have been installed. Finally, no seismic protection is provided in the uncontrolled control configuration (SubFigure 9(d)), which will be used as a reference in the performance assessments.

The section has been structured in three parts. First, the results presented in Section 2 are applied to obtain a second-order model for the three-building system. Next, suitable state-space models are derived. Finally, a state-feedback LQR controller is designed to drive the active local feedback control system implemented in building 2 .

To compute the LQR local controller, the following particular values of the building parameters have been used: $m_{i}^{j}=1.3 \times 10^{6} \mathrm{~kg}, c_{i}^{j}=10^{5} \mathrm{Ns} / \mathrm{m}, k_{i}^{1}=2.0 \times 10^{9} \mathrm{~N} / \mathrm{m}, k_{i}^{2}=$ $4 \times 10^{9} \mathrm{~N} / \mathrm{m}, k_{i}^{3}=2.0 \times 10^{9} \mathrm{~N} / \mathrm{m}$, for $1 \leq j \leq 3,1 \leq i \leq n_{j}, n_{1}=3, n_{2}=5, n_{3}=2$. The linking elements are considered as pure dampers with a damping constant $\hat{c}_{i}^{j}=3.0 \times 10^{6} \mathrm{Ns} / \mathrm{m}$ and null stiffness; the value $\widehat{c}_{i}^{j}=0$ indicates that no linking element exists at the $i$ th level between buildings $B^{(j)}$ and $B^{(j+1)}$. The actuation elements $a_{i}^{2}, 1 \leq i \leq 5$ are assumed to be ideal force actuation devices, which are able to implement exactly the control actions $u_{i}^{2}(t)$ producing the opposite pairs of control forces represented in Figure $8(b)$. These values will also be used in the numerical simulations conducted in Section 4.

\subsection{Second-Order Model}

Let us consider the three-story building system displayed in Figure 8(a) as a lumped-mass planar system with displacements in the direction of the ground motion. In this case, the multibuilding system can be represented by the connected multistructure system shown in Figure 10. Using the results presented in the previous section, a second-order model in the form

$$
M \ddot{q}(t)+C \dot{q}(t)+K q(t)=T_{u} u(t)+T_{\omega} \omega(t),
$$




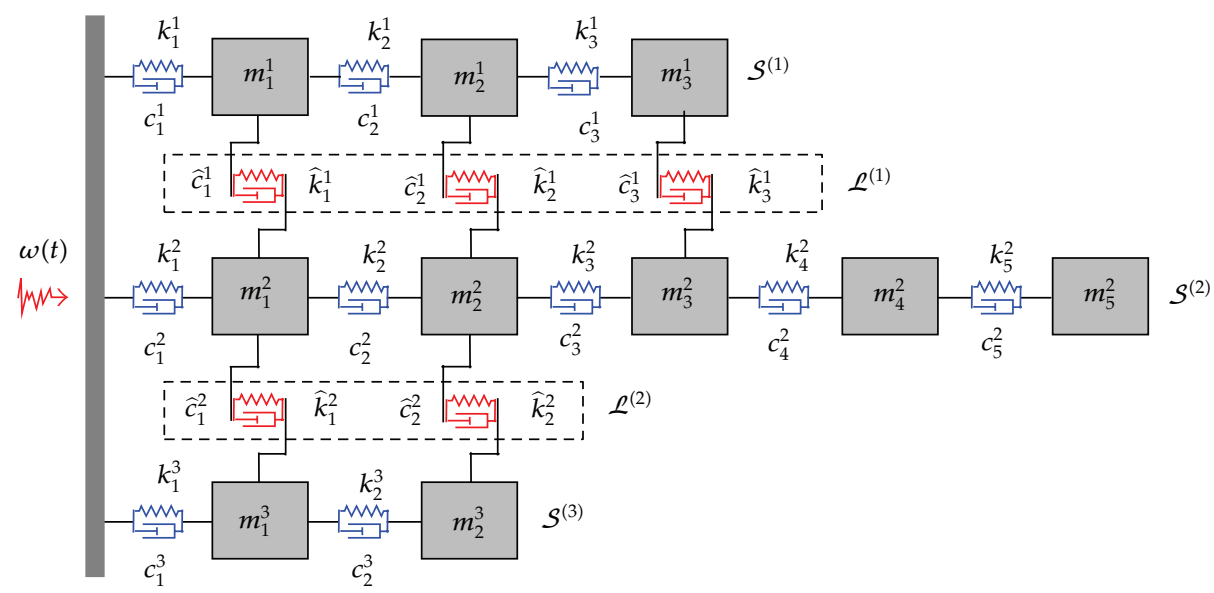

Figure 10: Connected three-building system.

to describe the buildings motion can be easily obtained. The overall vector of story displacements with respect to the ground is

$$
q(t)=\left[q_{1}^{1}(t), q_{2}^{1}(t), q_{3}^{1}(t), q_{1}^{2}(t), q_{2}^{2}(t), q_{3}^{2}(t), q_{4}^{2}(t), q_{5}^{2}(t), q_{1}^{3}(t), q_{2}^{3}(t)\right]^{T}
$$

where $q_{i}^{j}(t)$ represents the displacement of the $i$ th story in the $j$ th building. The mass matrix is

$$
M=\left[\begin{array}{ccc}
M^{(1)} & {[0]_{3 \times 5}} & {[0]_{3 \times 2}} \\
{[0]_{5 \times 3}} & M^{(2)} & {[0]_{5 \times 2}} \\
{[0]_{2 \times 3}} & {[0]_{2 \times 5}} & M^{(3)}
\end{array}\right],
$$

with

$$
M^{(1)}=\left[\begin{array}{ccc}
m_{1}^{1} & 0 & 0 \\
0 & m_{2}^{1} & 0 \\
0 & 0 & m_{3}^{1}
\end{array}\right], \quad M^{(2)}=\left[\begin{array}{ccccc}
m_{1}^{2} & 0 & 0 & 0 & 0 \\
0 & m_{2}^{2} & 0 & 0 & 0 \\
0 & 0 & m_{3}^{2} & 0 & 0 \\
0 & 0 & 0 & m_{4}^{2} & 0 \\
0 & 0 & 0 & 0 & m_{5}^{2}
\end{array}\right], \quad M^{(3)}=\left[\begin{array}{cc}
m_{1}^{3} & 0 \\
0 & m_{2}^{3}
\end{array}\right]
$$

The total damping matrix can be written in the form

$$
C=\bar{C}+\widehat{C},
$$


where

$$
\begin{gathered}
\bar{C}=\left[\begin{array}{ccc}
C^{(1)} & {[0]_{3 \times 5}} & {[0]_{3 \times 2}} \\
{[0]_{5 \times 3}} & C^{(2)} & {[0]_{5 \times 2}} \\
{[0]_{2 \times 3}} & {[0]_{2 \times 5}} & C^{(3)}
\end{array}\right], \\
C^{(1)}=\left[\begin{array}{ccc}
c_{1}^{1}+c_{2}^{1} & -c_{2}^{1} & 0 \\
-c_{2}^{1} & c_{2}^{1}+c_{3}^{1} & -c_{3}^{1} \\
0 & -c_{3}^{1} & c_{3}^{1}
\end{array}\right], \quad C^{(3)}=\left[\begin{array}{cccc}
c_{1}^{3}+c_{2}^{3} & -c_{2}^{3} \\
-c_{2}^{3} & c_{2}^{3}
\end{array}\right], \\
C^{(2)}=\left[\begin{array}{ccccc}
c_{1}^{2}+c_{2}^{2} & -c_{2}^{2} & 0 & 0 & 0 \\
-c_{2}^{2} & c_{2}^{2}+c_{3}^{2} & -c_{3}^{2} & 0 & 0 \\
0 & -c_{3}^{2} & c_{3}^{2}+c_{4}^{2} & -c_{4}^{2} & 0 \\
0 & 0 & -c_{4}^{2} & c_{4}^{2}+c_{5}^{2} & -c_{5}^{2} \\
0 & 0 & 0 & -c_{5}^{2} & c_{5}^{2}
\end{array}\right],
\end{gathered}
$$

and the matrix corresponding to the linking elements $\widehat{C}$ has the following block tridiagonal structure:

$$
\begin{gathered}
\widehat{C}=\left[\begin{array}{ccc}
{\left[\widehat{C}^{(1)}\right]_{3 \times 3}} & -\left[\widehat{C}^{(1)}\right]_{3 \times 5} & {[0]_{3 \times 2}} \\
-\left[\widehat{C}^{(1)}\right]_{5 \times 3} & {\left[\widehat{C}^{(1)}\right]_{5 \times 5}+\left[\widehat{C}^{(2)}\right]_{5 \times 5}} & -\left[\widehat{C}^{(2)}\right]_{5 \times 2} \\
{[0]_{2 \times 3}} & -\left[\widehat{C}^{(2)}\right]_{2 \times 5} & {\left[\widehat{C}^{(2)}\right]_{2 \times 2}}
\end{array}\right], \\
\widehat{C}^{(1)}=\left[\begin{array}{ccc}
\widehat{c}_{1}^{1} & 0 & 0 \\
0 & \widehat{c}_{2}^{1} & 0 \\
0 & 0 & \widehat{c}_{3}^{1}
\end{array}\right], \quad \widehat{C}^{(2)}=\left[\begin{array}{cc}
\widehat{c}_{1}^{2} & 0 \\
0 & \widehat{c}_{2}^{2}
\end{array}\right],
\end{gathered}
$$

where $\left[\widehat{C}^{(j)}\right]_{r \times s}$ denotes the $r \times s$ zero-extension of $\widehat{C}^{(j)}$, for example

$$
\left[\widehat{C}^{(1)}\right]_{5 \times 5}=\left[\begin{array}{ccccc}
\widehat{c}_{1}^{1} & 0 & 0 & 0 & 0 \\
0 & \widehat{c}_{2}^{1} & 0 & 0 & 0 \\
0 & 0 & \widehat{c}_{3}^{1} & 0 & 0 \\
0 & 0 & 0 & 0 & 0 \\
0 & 0 & 0 & 0 & 0
\end{array}\right], \quad\left[\widehat{C}^{(2)}\right]_{5 \times 2}=\left[\begin{array}{cc}
\widehat{c}_{1}^{2} & 0 \\
0 & \widehat{c}_{2}^{2} \\
0 & 0 \\
0 & 0 \\
0 & 0
\end{array}\right]
$$

To obtain the total stiffness matrix

$$
K=\bar{K}+\widehat{K}
$$


matrices $\bar{K}, \widehat{K}$ can be computed replacing the damping coefficients $c_{i}^{j}, \widehat{c}_{i}^{j}$ by the corresponding stiffness coefficients $k_{i}^{j}, \widehat{k}_{i}^{j}$ in (3.7), (3.8), (3.10), and matrices $C^{(j)}, \widehat{C}^{(j)}$ by $K^{(j)}, \widehat{K}^{(j)}$ in (3.6), (3.9). For the active-passive control configuration depicted in Figure $9(\mathrm{a})$, the vector of control actions is

$$
u(t)=\left[0,0,0, u_{1}^{2}(t), u_{2}^{2}(t), u_{3}^{2}(t), u_{4}^{2}(t), u_{5}^{2}(t), 0,0\right]^{T},
$$

and the control location matrix $T_{u}$ to produce the corresponding control forces can be written as follows:

$$
T_{u}=\left[\begin{array}{ccc}
{[0]_{3 \times 3}} & {[0]_{3 \times 5}} & {[0]_{3 \times 2}} \\
{[0]_{5 \times 3}} & T_{u}^{(2)} & {[0]_{5 \times 2}} \\
{[0]_{2 \times 3}} & {[0]_{2 \times 5}} & {[0]_{2 \times 2}}
\end{array}\right], \quad T_{u}^{(2)}=\left[\begin{array}{ccccc}
1 & -1 & 0 & 0 & 0 \\
0 & 1 & -1 & 0 & 0 \\
0 & 0 & 1 & -1 & 0 \\
0 & 0 & 0 & 1 & -1 \\
0 & 0 & 0 & 0 & 1
\end{array}\right] .
$$

Finally, the disturbance input matrix is

$$
T_{w}=-M[1]_{10 \times 1} .
$$

\subsection{First-Order State-Space Model}

Now, we take the state vector

$$
x(t)=\left[\begin{array}{l}
q(t) \\
\dot{q}(t)
\end{array}\right]
$$

and derive the first-order state-space model

$$
\begin{aligned}
\dot{x}(t) & =A x(t)+B u(t)+E \omega(t), \\
y(t) & =C_{y} x(t),
\end{aligned}
$$

where the state, control, and disturbance input matrices are, respectively,

$$
A=\left[\begin{array}{cc}
{[0]_{10 \times 10}} & I_{10} \\
-M^{-1} K & -M^{-1} C
\end{array}\right], \quad B=\left[\begin{array}{c}
{[0]_{10 \times 10}} \\
M^{-1} T_{u}
\end{array}\right], \quad E=\left[\begin{array}{c}
{[0]_{10 \times 1}} \\
-[1]_{10 \times 1}
\end{array}\right] .
$$

Regarding the output, we consider two different cases: interstory drifts and interbuilding approaches. The interstory drifts represent the relative displacements between consecutive stories in the $j$ th building and are defined by

$$
\begin{aligned}
& \left\{y_{s}\right\}_{1}^{j}(t)=q_{1}^{j}(t), \\
& \left\{y_{s}\right\}_{i}^{j}(t)=q_{i}^{j}(t)-q_{i-1}^{j}(t), \quad 1<i \leq n_{j},
\end{aligned}
$$


where $n_{j}$ is the number of stories in building $\mathbb{B}^{(j)}$. The vector of interstory drifts

$$
y_{s}(t)=\left[\left\{y_{s}\right\}_{1^{\prime}}^{1}\left\{y_{s}\right\}_{2^{\prime}}^{1}\left\{y_{s}\right\}_{3^{\prime}}^{1}\left\{y_{s}\right\}_{1^{\prime}}^{2}\left\{y_{s}\right\}_{2^{\prime}}^{2}\left\{y_{s}\right\}_{3^{\prime}}^{2}\left\{y_{s}\right\}_{4^{\prime}}^{2}\left\{y_{s}\right\}_{5^{\prime}}^{2},\left\{y_{s}\right\}_{1^{\prime}}^{3}\left\{y_{s}\right\}_{2}^{3}\right]^{T}
$$

can be obtained with the output matrix

$$
C_{y_{s}}=\left[\begin{array}{cccc}
C_{y_{s}}^{(1)} & {[0]_{3 \times 5}} & {[0]_{3 \times 2}} & {[0]_{3 \times 10}} \\
{[0]_{5 \times 3}} & C_{y_{s}}^{(2)} & {[0]_{5 \times 2}} & {[0]_{5 \times 10}} \\
{[0]_{2 \times 3}} & {[0]_{2 \times 5}} & C_{y_{s}}^{(3)} & {[0]_{2 \times 10}}
\end{array}\right],
$$

where

$$
\begin{aligned}
& C_{y_{s}}^{(1)}=\left[\begin{array}{ccc}
1 & 0 & 0 \\
-1 & 1 & 0 \\
0 & -1 & 1
\end{array}\right], \quad C_{y_{s}}^{(2)}=\left[\begin{array}{ccccc}
1 & 0 & 0 & 0 & 0 \\
-1 & 1 & 0 & 0 & 0 \\
0 & -1 & 1 & 0 & 0 \\
0 & 0 & -1 & 1 & 0 \\
0 & 0 & 0 & -1 & 1
\end{array}\right], \\
& C_{y_{s}}^{(3)}=\left[\begin{array}{cc}
1 & 0 \\
-1 & 1
\end{array}\right] .
\end{aligned}
$$

The interbuilding approaches describe the approaching between the stories placed at the $i$ th level in the adjacent buildings $\boldsymbol{B}^{(j)}, \boldsymbol{B}^{(j+1)}$ and are defined by

$$
\left\{y_{a}\right\}_{i}^{j}(t)=-\left(q_{i}^{j+1}(t)-q_{i}^{j}(t)\right), \quad 1 \leq i \leq r_{j}, 1 \leq j \leq 2,
$$

where $r_{j}=\min \left(n_{j}, n_{j+1}\right)$. The vector of interbuilding approaches

$$
y_{a}(t)=\left[\left\{y_{a}\right\}_{1}^{1}(t),\left\{y_{a}\right\}_{2}^{1}(t),\left\{y_{a}\right\}_{3}^{1}(t),\left\{y_{a}\right\}_{1}^{2}(t),\left\{y_{a}\right\}_{2}^{2}(t)\right]^{T}
$$

can be computed with the output matrix

$$
C_{y_{a}}=\left[\begin{array}{cccc}
I_{3} & -\left[I_{3}\right]_{3 \times 5} & {[0]_{3 \times 2}} & {[0]_{3 \times 10}} \\
{[0]_{2 \times 3}} & {\left[I_{2}\right]_{2 \times 5}} & -I_{2} & {[0]_{2 \times 10}}
\end{array}\right]
$$

Finally, let us suppose that the state-feedback controller

$$
u^{(j)}(t)=G^{(j)} x^{(j)}(t)
$$


has been computed to drive a local active control system in $\boldsymbol{B}^{(j)}$. We write the local vector of control actions as

$$
u^{(j)}(t)=G^{(j)} x^{(j)}(t)=\left[G_{1}^{(j)} \mid G_{2}^{(j)}\right]\left[\begin{array}{l}
q^{(j)}(t) \\
\dot{q}^{(j)}(t)
\end{array}\right]
$$

where matrices $G_{1}^{(j)}, G_{2}^{(j)}$ are obtained by splitting the control matrix $G^{(j)}$ after the $n_{j}$-th column. The seismic response of the overall three-building system for different active-passive control configurations can be computed using the closed-loop state-space model as follows:

$$
\begin{aligned}
& \dot{x}(t)=\bar{A} x(t)+E w(t), \\
& y(t)=C_{y} x(t),
\end{aligned}
$$

where the state matrix $\bar{A}=A+B G$ can be obtained using the matrices $A, B, E$ given in (3.18), and the overall control matrix

$$
G=\left[\begin{array}{cccccc}
\bar{G}_{1}^{(1)} & {[0]_{3 \times 5}} & {[0]_{3 \times 2}} & \bar{G}_{2}^{(1)} & {[0]_{3 \times 5}} & {[0]_{3 \times 2}} \\
{[0]_{5 \times 3}} & \bar{G}_{1}^{(2)} & {[0]_{5 \times 2}} & {[0]_{5 \times 3}} & \bar{G}_{2}^{(2)} & {[0]_{5 \times 2}} \\
{[0]_{2 \times 3}} & {[0]_{2 \times 5}} & \bar{G}_{1}^{(3)} & {[0]_{2 \times 3}} & {[0]_{2 \times 5}} & \bar{G}_{2}^{(3)}
\end{array}\right]
$$

with

$$
\bar{G}_{i}^{(j)}= \begin{cases}G_{i}^{(j)}, & \text { if } \boldsymbol{B}^{(j)} \text { is actively controlled, } \\ {[0]_{n_{j} \times n_{j}},} & \text { otherwise. }\end{cases}
$$

In particular, for the active-passive control configuration depicted in Figure 9(a), the overall control matrix has the form

$$
G=\left[\begin{array}{cccccc}
{[0]_{3 \times 3}} & {[0]_{3 \times 5}} & {[0]_{3 \times 2}} & {[0]_{3 \times 3}} & {[0]_{3 \times 5}} & {[0]_{3 \times 2}} \\
{[0]_{5 \times 3}} & \bar{G}_{1}^{(2)} & {[0]_{5 \times 2}} & {[0]_{5 \times 3}} & \bar{G}_{2}^{(2)} & {[0]_{5 \times 2}} \\
{[0]_{2 \times 3}} & {[0]_{2 \times 5}} & {[0]_{2 \times 2}} & {[0]_{2 \times 3}} & {[0]_{2 \times 5}} & {[0]_{2 \times 2}}
\end{array}\right]
$$

\subsection{Local State-Feedback Controller Design}

To compute a local state-feedback LQR controller [30] for the actuation system in building $B^{(2)}$, we consider the local second-order model

$$
M^{(2)} \ddot{q}^{(2)}(t)+C^{(2)} \dot{q}^{(2)}(t)+K^{(2)} q^{(2)}(t)=T_{u}^{(2)} u^{(2)}(t),
$$


where

$$
q^{(2)}(t)=\left[q_{1}^{2}(t), q_{2}^{2}(t), q_{3}^{2}(t), q_{4}^{2}(t), q_{5}^{2}(t)\right]^{T}
$$

is the vector of story displacements relative to the ground,

$$
u^{(2)}(t)=\left[u_{1}^{2}(t), u_{2}^{2}(t), u_{3}^{2}(t), u_{4}^{2}(t), u_{5}^{2}(t)\right]^{T}
$$

is the vector of control actions, and matrices $M^{(2)}, C^{(2)}, K^{(2)}, T_{u}^{(2)}$ have been given in the previous subsection. From (3.32), we obtain the first-order state-space model

$$
\begin{aligned}
& \dot{x}^{(2)}(t)=A^{(2)} x^{(2)}(t)+B^{(2)} u^{(2)}(t), \\
& \left\{y_{s}\right\}^{(2)}(t)=C_{y_{s}}^{(2)} x^{(2)}(t),
\end{aligned}
$$

with local state vector

$$
x^{(2)}(t)=\left[\begin{array}{l}
q^{(2)}(t) \\
\dot{q}^{(2)}(t)
\end{array}\right]
$$

state matrix

$$
A^{(2)}=\left[\begin{array}{cc}
{[0]_{5 \times 5}} & I_{5} \\
-\left\{M^{(2)}\right\}^{-1} K^{(2)} & -\left\{M^{(2)}\right\}^{-1} C^{(2)}
\end{array}\right],
$$

and control input matrix

$$
B^{(2)}=\left[\begin{array}{c}
{[0]_{5 \times 5}} \\
\left\{M^{(2)}\right\}^{-1} T_{u}^{(2)}
\end{array}\right]
$$

To obtain the local vector of interstory drifts

$$
\left\{y_{s}\right\}^{(2)}(t)=\left[\left\{y_{s}\right\}_{1}^{2}(t),\left\{y_{s}\right\}_{2}^{2}(t),\left\{y_{s}\right\}_{3}^{2}(t),\left\{y_{s}\right\}_{4}^{2}(t),\left\{y_{s}\right\}_{5}^{2}(t)\right]^{T}
$$

we take the matrix $C_{y_{s}}^{(2)}$ given in (3.22) and define the local output matrix

$$
\bar{C}_{y_{s}}^{(2)}=\left[C_{y_{s}}^{(2)}[0]_{5 \times 5}\right] .
$$

Next, we consider the weighting matrices

$$
Q^{(2)}=\left\{\bar{C}_{y_{s}}^{(2)}\right\}^{T} \bar{C}_{y_{s}}^{(2)}, \quad R^{(2)}=10^{-17.5} \times I_{5}
$$




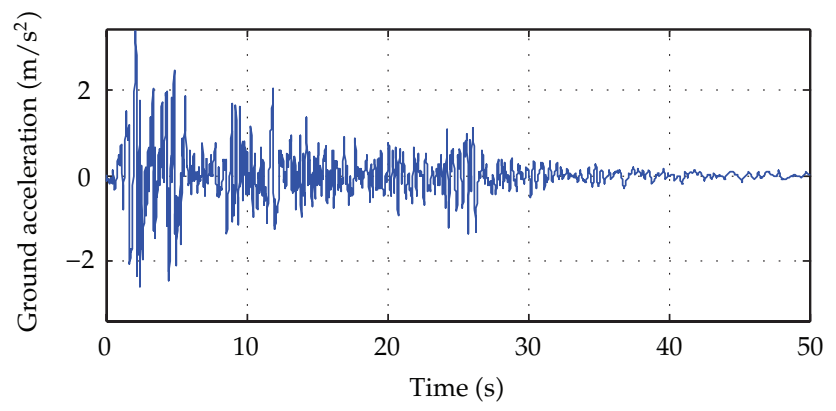

Figure 11: North-South El Centro 1940 seismic record.

and define the quadratic cost function

$$
\begin{aligned}
J^{(2)}\left(x^{(2)}, u^{(2)}\right) & =\int_{0}^{\infty}\left[\left\{x^{(2)}(t)\right\}^{T} Q^{(2)} x^{(2)}(t)+\left\{u^{(2)}(t)\right\}^{T} R^{(2)} u^{(2)}(t)\right] d t \\
& =\int_{0}^{\infty}\left[\left\{y_{s}^{(2)}(t)\right\}^{T} y_{s}^{(2)}(t)+\left\{u^{(2)}(t)\right\}^{T} R^{(2)} u^{(2)}(t)\right] d t
\end{aligned}
$$

to compute a local state-feedback LQR controller

$$
u^{(2)}(t)=G^{(2)} x^{(2)}(t)
$$

with the following control gain matrix:

$$
\begin{aligned}
& G^{(2)} \\
& =10^{7} \times\left[\begin{array}{cccccccccc}
-3.9335 & 0.0000 & 0.0000 & 0.0000 & 0.0000 & -0.8574 & -0.3617 & -0.2497 & -0.2051 & -0.1878 \\
3.9335 & -3.9335 & 0.0000 & 0.0000 & 0.0000 & 0.4957 & -0.7454 & -0.3171 & -0.2323 & -0.2051 \\
0.0000 & 3.9335 & -3.9335 & 0.0000 & 0.0000 & 0.1120 & 0.5403 & -0.7280 & -0.3171 & -0.2497 \\
0.0000 & 0.0000 & 3.9335 & -3.9335 & 0.0000 & 0.0446 & 0.1294 & 0.5403 & -0.7454 & -0.3617 \\
0.0000 & 0.0000 & 0.0000 & 3.9335 & -3.9335 & 0.0173 & 0.0446 & 0.1120 & 0.4957 & -0.8574
\end{array}\right]
\end{aligned}
$$

\section{Numerical Simulations}

In this section, the vibrational response of the three-building system presented in Section 3 is computed for several control configurations. Specifically, the maximum absolute interstory drifts and maximum interbuilding approaches are computed for three control configurations: (a) active-passive, (b) passive, and (c) uncoupled-active, which are schematically depicted in Figures 9(a), 9(b), and 9(c). The vibrational response of the uncontrolled system (SubFigure $9(\mathrm{~d})$ ) is also computed, and it is used as a natural reference in the performance assessment. In all the cases, the full-scale North-South El Centro 1940 seismic record obtained at the Imperial Valley Irrigation District substation in El Centro, CA, during the Imperial Valley earthquake of May 18, 1940, has been used as a ground acceleration input (see Figure 11).

The maximum absolute interstory drifts are displayed in Figure 12. Looking at the central graphic, the excellent behavior of the active-passive (black asterisks) and the 

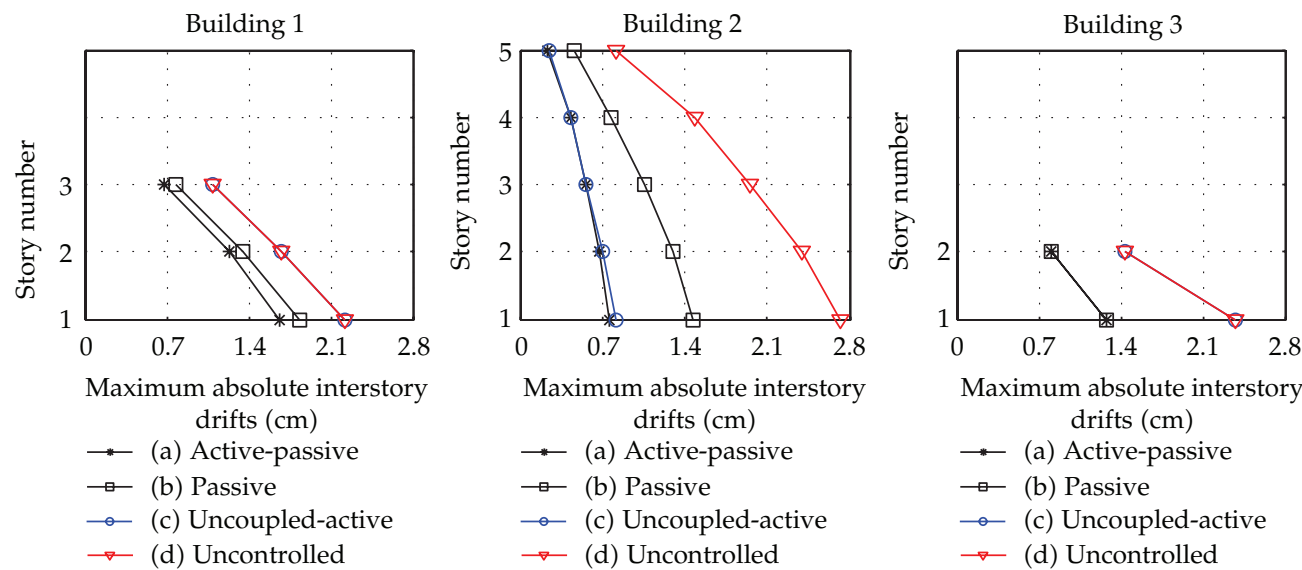

Figure 12: Maximum absolute interstory drifts for the North-South El Centro 1940 seismic excitation.

Table 1: Percentages of reduction in maximum absolute interstory drifts with respect to the uncontrolled response.

\begin{tabular}{lcccccccccc}
\hline & \multicolumn{3}{c}{ Building 1 } & \multicolumn{3}{c}{ Building 2 } & \multicolumn{2}{c}{ Building 3 } \\
& $\left\{y_{s}\right\}_{1}^{1}$ & $\left\{y_{s}\right\}_{2}^{1}$ & $\left\{y_{s}\right\}_{3}^{1}$ & $\left\{y_{s}\right\}_{1}^{2}$ & $\left\{y_{s}\right\}_{2}^{2}$ & $\left\{y_{s}\right\}_{3}^{2}$ & $\left\{y_{s}\right\}_{4}^{2}$ & $\left\{y_{s}\right\}_{5}^{2}$ & $\left\{y_{s}\right\}_{1}^{3}$ & $\left\{y_{s}\right\}_{2}^{3}$ \\
\hline (a) Active-passive & 24.7 & 26.7 & 37.4 & 72.4 & 71.7 & 71.3 & 71.1 & 71.5 & 43.3 & 43.7 \\
(b) Passive & 17.3 & 19.3 & 27.9 & 40.1 & 45.5 & 45.8 & 47.3 & 43.2 & 46.4 & 44.0 \\
(c) Uncoupled-active & 0 & 0 & 0 & 70.1 & 70.3 & 71.0 & 70.3 & 69.9 & 0 & 0 \\
\hline
\end{tabular}

uncoupled-active (blue circles) control configurations can be clearly appreciated. In fact, the data in Table 1 indicate that these active control configurations attain reductions of about $70 \%$ in the peak interstory drift values with respect to the uncontrolled response. For the lateral buildings, however, the situation is totally different. In this case, the active-passive control configuration produces a lower but still significant reduction of the interstory drifts, while no seismic protection is provided by the uncoupled-active configuration.

Regarding the interbuilding approaches, we can see in Figure 13 that interbuilding separations of about $7.5 \mathrm{~cm}$ would have resulted in interbuilding collisions for the uncontrolled configuration. In contrast, interbuilding separations of about $2.5 \mathrm{~cm}$ can be considered safe for the active-passive control configuration. An important reduction in the interbuilding approaches is also achieved by the uncoupled-active configuration, but the data in Table 2 indicate that the percentages of reduction obtained by this configuration are about 25 points inferior to those obtained by the active-passive control configuration.

To complete the comparison between the active-passive and the uncoupled-active configurations, the corresponding maximum absolute control efforts are presented in Table 3. The values in the table indicate that the active-passive configuration requires a slightly higher level of control effort. However, considering the superior performance exhibited by the active-passive configuration, the extra cost is certainly small.

The behavior of the passive control configuration is also remarkable. Despite its simplicity and null power consumption, percentages of reduction in the interstory drifts peak values of about $45 \%$ are achieved in buildings 2 and 3 and around $20 \%$ in building 1. Reductions of about $60 \%$ are also produced for the interbuilding approaches. 

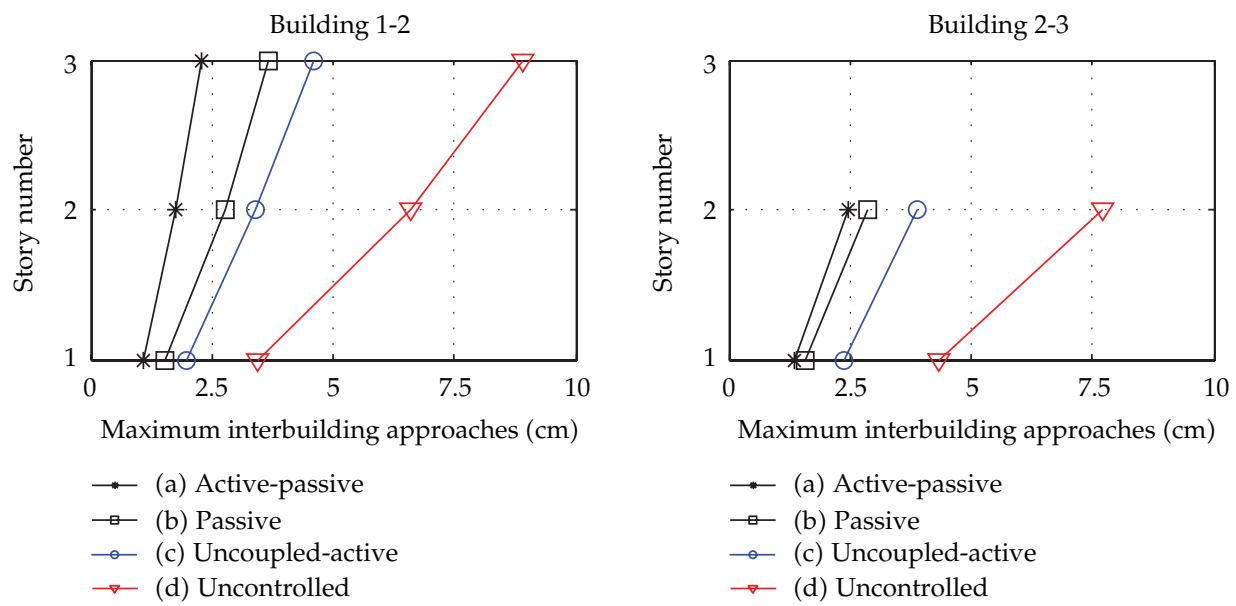

Figure 13: Maximum interbuilding approaches for the North-South El Centro 1940 seismic excitation.

Table 2: Percentages of reduction in maximum interbuilding approaches with respect to the uncontrolled response.

\begin{tabular}{lccccc}
\hline & \multicolumn{3}{c}{ Buildings 1-2 } & \multicolumn{2}{c}{ Buildings 2-3 } \\
& $\left\{y_{a}\right\}_{1}^{1}$ & $\left\{y_{a}\right\}_{2}^{1}$ & $\left\{y_{a}\right\}_{3}^{1}$ & $\left\{y_{a}\right\}_{1}^{2}$ & $\left\{y_{a}\right\}_{2}^{2}$ \\
\hline (a) Active-passive & 68.3 & 73.1 & 74.2 & 68.7 & 68.3 \\
(b) Passive & 55.4 & 57.8 & 58.6 & 63.8 & 63.7 \\
(c) Uncoupled-active & 43.3 & 48.6 & 48.5 & 45.5 & 49.9 \\
\hline
\end{tabular}

Table 3: Maximum absolute control forces exerted by actuation devices in building 2 .

\begin{tabular}{lccccc}
\hline & & \multicolumn{4}{c}{ Control actions in $\boldsymbol{B}^{(2)}\left(\times 10^{6} \mathrm{~N}\right)$} \\
& $a_{1}^{2}$ & $a_{2}^{2}$ & $a_{3}^{2}$ & $a_{4}^{2}$ & $a_{5}^{2}$ \\
\hline (a) Active-passive & 4.64 & 4.22 & 3.48 & 2.49 & 1.30 \\
(c) Uncoupled-active & 4.33 & 3.88 & 3.14 & 2.27 & 1.26 \\
\hline
\end{tabular}

Finally, it should be highlighted the robustness of the active-passive control configuration against failures in the local active control system. Actually, in case of a full failure of the active control system, the passive level of seismic protection can still be guaranteed by the passive-active control configuration. In contrast, the same kind of failure in the uncoupledactive configuration would produce a total loss of seismic protection.

\section{Final Remarks and Conclusions}

In this work, a mathematical model to compute the overall vibrational response of connected multistructure mechanical systems has been presented. Using the proposed model and following the connected control method approach, structural vibration control strategies for seismic protection of multibuilding systems can be efficiently designed. As a practical 
application of the new ideas, different control configurations for seismic protection of a particular three-building system have been designed. For these control configurations, numerical simulations of the three-building system vibrational response have been conducted using the full-scale North-South 1940 seismic record as a seismic excitation. The simulation results come to confirm the excellent properties of control configurations that combine passive interbuilding dampers with local feedback control systems implemented in the buildings. These hybrid active-passive control strategies possess the good properties of passive control systems and also have the high-performance characteristics of active control systems. Moreover, active-passive control configurations can be properly designed for multibuilding systems that require different levels of seismic protection and are also remarkably robust against failures in the local feedback control systems. Finally, it is worth highlighting that the proposed active-passive control strategy is compatible with practically any control design methodology of the local feedback control systems and also with semiactive implementations of the actuation systems. Consequently, further research effort needs to be aimed at exploring more complex scenarios involving issues of practical interest such as wireless implementation of the communications systems [31], actuator saturation [32], actuation and sensor failures [33], structural information constraints [34,35], uncertain stochastic networked systems [3638], or limited frequency domain [39].

\section{Acknowledgments}

This work has been partially supported by the Spanish Ministry of Economy and Competitiveness through the Grant DPI2011-25567-C02 and by the Norwegian Center of Offshore Wind Energy (NORCOWE) under Grant 193821/S60 from the Research Council of Norway (RCN).

\section{References}

[1] S. A. Anagnostopoulos, "Building pounding re-examined: how serious a problem is it?" In Eleventh World Conference of Earthquake Engineering, Elsevier Science, 1996.

[2] K. T. Chau, X. X. Wei, X. Guo, and C. Y. Shen, "Experimental and theoretical simulations of seismic poundings between two adjacent structures," Earthquake Engineering and Structural Dynamics, vol. 32, no. 4, pp. 537-554, 2003.

[3] P. Komodromos, P. C. Polycarpou, L. Papaloizou, and M. C. Phocas, "Response of seismically isolated buildings considering poundings," Earthquake Engineering and Structural Dynamics, vol. 36, no. 12, pp. 1605-1622, 2007.

[4] D. Lopez-Garcia and T. T. Soong, "Assessment of the separation necessary to prevent seismic pounding between linear structural systems," Probabilistic Engineering Mechanics, vol. 24, no. 2, pp. 210-223, 2009.

[5] P. C. Polycarpou and P. Komodromos, "Earthquake-induced poundings of a seismically isolated building with adjacent structures," Engineering Structures, vol. 32, no. 7, pp. 1937-1951, 2010.

[6] Y. L. Xu, Q. He, and J. M. Ko, "Dynamic response of damper-connected adjacent buildings under earthquake excitation," Engineering Structures, vol. 21, no. 2, pp. 135-148, 1999.

[7] W. S. Zhang and Y. L. Xu, "Dynamic characteristics and seismic response of adjacent buildings linked by discrete dampers," Earthquake Engineering and Structural Dynamics, vol. 28, pp. 1163-1185, 1999.

[8] Y. Q. Ni, J. M. Ko, and Z. G. Ying, "Random seismic response analysis of adjacent buildings coupled with non-linear hysteretic dampers," Journal of Sound and Vibration, vol. 246, no. 3, pp. 403-417, 2001.

[9] Z. Yang, Y. L. Xu, and X. L. Lu, "Experimental seismic study of adjacent buildings with fluid dampers," Journal of Structural Engineering, vol. 129, no. 2, pp. 197-205, 2003.

[10] V. A. Matsagar and R. S. Jangid, "Viscoelastic damper connected to adjacent structures involving seismic isolation," Journal of Civil Engineering and Management, vol. 11, no. 4, pp. 309-322, 2005. 
[11] A. V. Bhaskararao and R. S. Jangid, "Seismic response of adjacent buildings connected with friction dampers," Bulletin of Earthquake Engineering, vol. 4, no. 1, pp. 43-64, 2006.

[12] J. Kim, J. Ryu, and L. Chung, "Seismic performance of structures connected by viscoelastic dampers," Engineering Structures, vol. 28, no. 2, pp. 183-195, 2006.

[13] M. Basili and M. De Angelis, "Optimal passive control of adjacent structures interconnected with nonlinear hysteretic devices," Journal of Sound and Vibration, vol. 301, no. 1-2, pp. 106-125, 2007.

[14] K. Makita, R. E. Christenson, K. Seto, and T. Watanabe, “Optimal design strategy of connected control method for two dynamically similar structures," Journal of Engineering Mechanics, vol. 133, no. 12, pp. 1247-1257, 2007.

[15] C. C. Patel, "Dynamic response of viscous damper connected similar multi-degree of freedom structures," International Journal of Earth Sciences and Engineering, vol. 4, no. 6, pp. 1068-1071, 2011.

[16] H. P. Zhu, D. D. Ge, and X. Huang, "Optimum connecting dampers to reduce the seismic responses of parallel structures," Journal of Sound and Vibration, vol. 330, no. 9, pp. 1931-1949, 2011.

[17] R. E. Christenson, B. F. Spencer, N. Hori, and K. Seto, “Coupled building control using acceleration feedback," Computer-Aided Civil and Infrastructure Engineering, vol. 18, no. 1, pp. 4-18, 2003.

[18] Z. G. Ying, Y. Q. Ni, and J. M. Ko, "Stochastic optimal coupling-control of adjacent building structures," Computers and Structures, vol. 81, no. 30-31, pp. 2775-2787, 2003.

[19] R. E. Christenson, B. F. Spencer, E. A. Johnson, and K. Seto, “Coupled building control considering the effects of building/connector configuration," Journal of Structural Engineering, vol. 132, no. 6, pp. 853-863, 2006.

[20] H. Zhu, Y. Wen, and H. Iemura, "A study on interaction control for seismic response of parallel structures," Computers and Structures, vol. 79, no. 2, pp. 231-242, 2001.

[21] R. E. Christenson, B. F. Spencer, and E. A. Johnson, "Semiactive connected control method for adjacent multidegree-of-freedom buildings," Journal of Engineering Mechanics, vol. 133, no. 3, pp. 290-298, 2007.

[22] S. D. Bharti, S. M. Dumne, and M. K. Shrimali, "Seismic response analysis of adjacent buildings connected with MR dampers," Engineering Structures, vol. 32, no. 8, pp. 2122-2133, 2010.

[23] M. S. Shahidzadeh, H. Tarzi, and M. Dorfeshan, "Takagi-Sugeno fuzzy control of adjacent structures using MR dampers," Journal of Applied Sciences, vol. 11, no. 15, pp. 2816-2822, 2011.

[24] F. Palacios-Quiñonero, J. Rodellar, J. M. Rossell, and H. R. Karimi, “Active-passive control strategy for adjacent buildings," in Proceedings of the American Control Conference, San Francisco, Calif, USA, 2011.

[25] F. Palacios-Quiñonero, J. M. Rossell, J. Rodellar, and H. R. Karimi, "Active-passive decentralized $H_{\infty}$ control for adjacent buildings under seismic excitation," in Proceedings of the 18th IFAC World Congress, Milano, Italy, 2011.

[26] B. F. Spencer and S. Nagarajaiah, "State of the art of structural control," Journal of Structural Engineering, vol. 129, no. 7, pp. 845-856, 2003.

[27] Y. Ikeda, "Active and semi-active control of buildings in Japan," Journal of Japan Association for Earthquake Engineering, vol. 4, no. 3, pp. 278-282, 2004.

[28] H. Li and L. Huo, "Advances in structural control in civil engineering in China," Mathematical Problems in Engineering, Article ID 936081, pp. 1-23, 2010.

[29] F. Palacios-Quiñonero, J. M. Rossell, J. Rodellar, and R. Pons-López, "Passive-active vibration control for connected multi-building structures," in Proceedings of the 8th International Conference on Structural Dynamics (Eurodyn), pp. 1931-1938, 2011.

[30] K. Ogata, Modern Control Engineering, Prentice Hall, Upper Saddle River, NJ USA, 3rd edition, 1997.

[31] R. A. Swartz and J. P. Lynch, "Strategic network utilization in a wireless structural control system for seismically excited structures," Journal of Structural Engineering, vol. 135, no. 5, pp. 597-608, 2009.

[32] H. Du and J. Lam, "Energy-to-peak performance controller design for building via static output feedback under consideration of actuator saturation," Computers $\mathcal{E}$ Structures, vol. 84, no. 31-32, pp. 2277-2290, 2006.

[33] W. Zhang, Y. Chen, and H. Gao, "Energy-to-peak control for seismic-excited buildings with actuator faults and parameter uncertainties," Journal of Sound and Vibration, vol. 330, no. 4, pp. 581-602, 2011.

[34] F. Palacios-Quiñonero, J. M. Rossell, and H. R. Karimi, "Semi-decentralized strategies in structural vibration control," Modeling Identification and Control, vol. 32, no. 2, pp. 57-77, 2011.

[35] J. Rubió-Massegú, F. Palacios-Quiñonero, and J. M. Rossell, "Decentralized static output-feedback $H_{\infty}$ controller design for buildings under seismic excitation," Earthquake Engineering and Structural Dynamics, vol. 41, no. 7, pp. 1199-1205, 2012.

[36] H. Dong, Z. Wang, and H. Gao, “Distributed filtering for a class of time-varying systems over sensor networks with quantization errors and successive packet dropouts," IEEE Transactions on Signal Processing, vol. 60, no. 6, pp. 3164-3173, 2012. 
[37] Z. Wang, B. Shen, H. Shu, and G. Wei, "Quantized $H_{\infty}$ control for nonlinear stochastic time-delay systems with missing measurements," IEEE Transactions on Automatic Control, vol. 57, no. 6, pp. 14311444, 2012.

[38] Z. Wang, B. Shen, and X. Liu, " $H_{\infty}$ filtering with randomly occurring sensor saturations and missing measurements," Automatica, vol. 48, no. 3, pp. 556-562, 2012.

[39] Y. Chen, W. Zhang, and H. Gao, "Finite frequency $H_{\infty}$ control for building under earthquake excitation," Mechatronics, vol. 20, no. 1, pp. 128-142, 2010. 


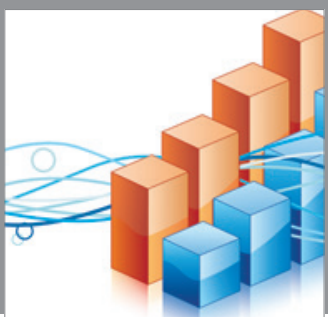

Advances in

Operations Research

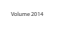

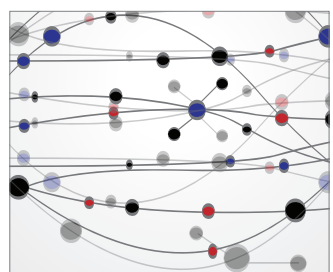

\section{The Scientific} World Journal
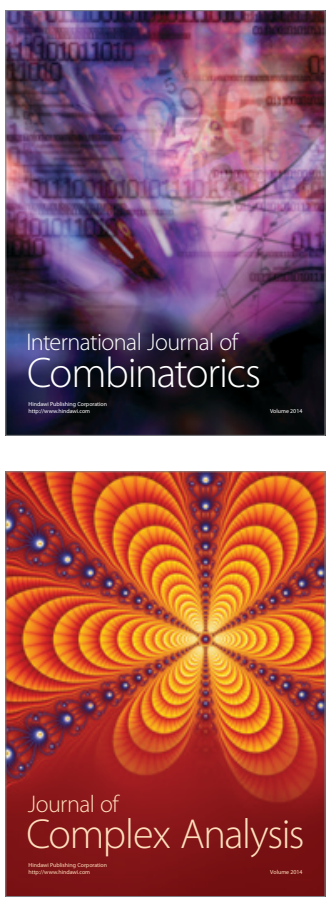

International Journal of

Mathematics and

Mathematical

Sciences
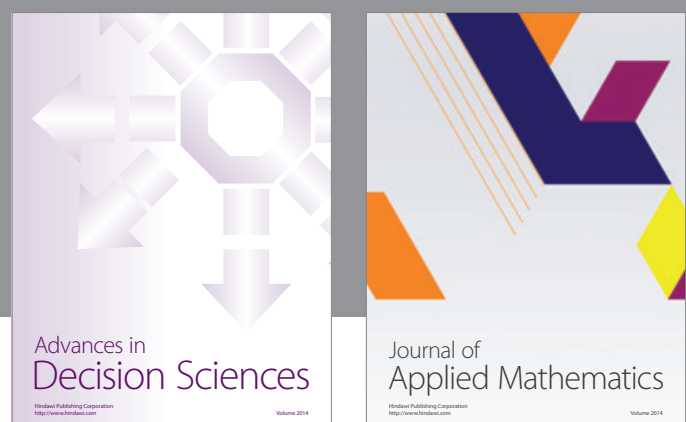

Journal of

Applied Mathematics
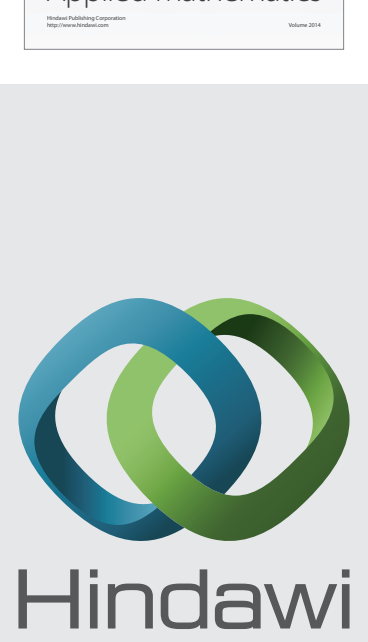

Submit your manuscripts at http://www.hindawi.com
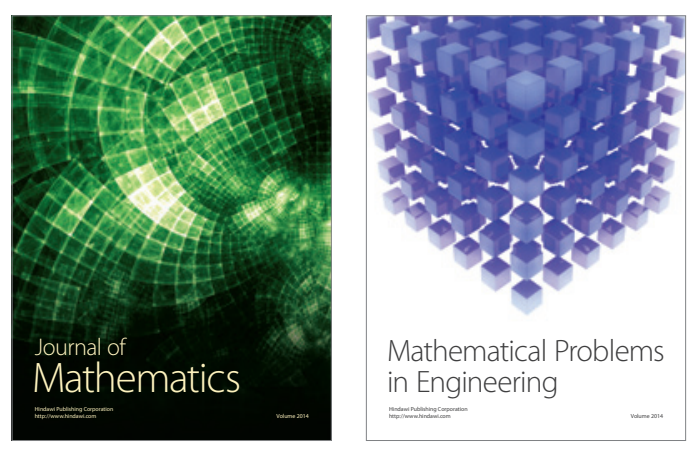

Mathematical Problems in Engineering
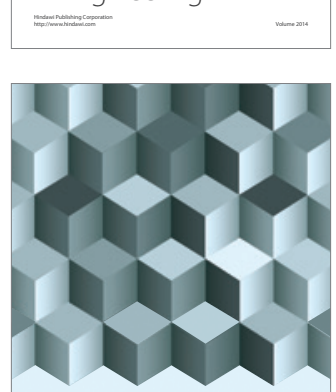

Journal of

Function Spaces
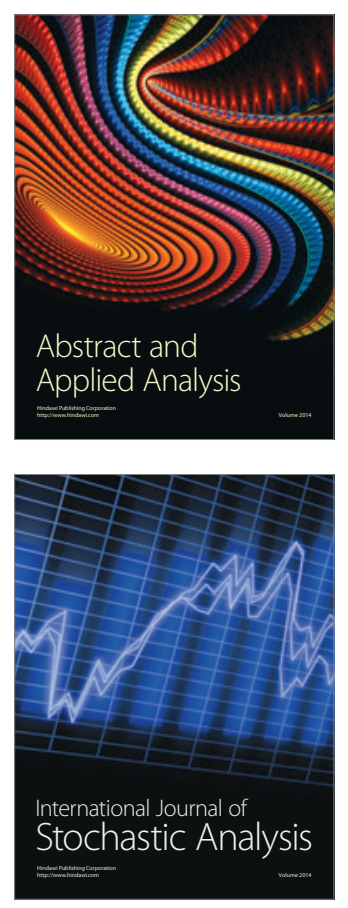

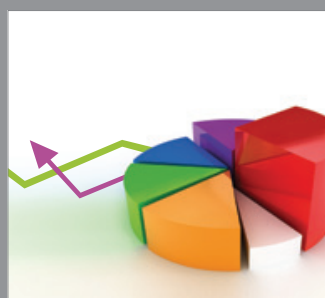

ournal of

Probability and Statistics

Promensencen
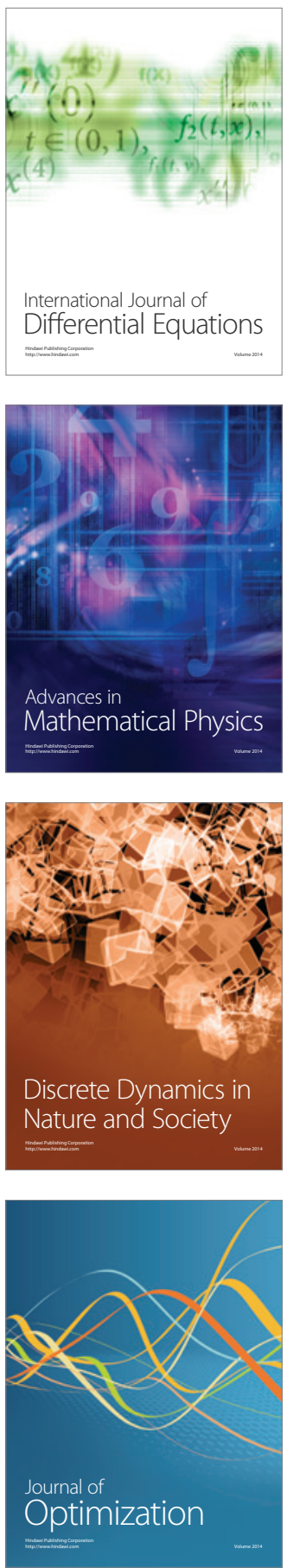